\title{
A new correlation for predicting the hydrothermal characteristics over flat tube banks
}

Djamel SAHEL, Houari AMEUR, Warda BOUDAOUD

DOI: 10.30464/jmee.2019.3.3.273

Cite this article as:

Sahel D., Ameur H., Boudaoud W. A new correlation for predicting the hydrothermal characteristics over flat tube banks. Journal of Mechanical and Energy Engineering, Vol. 3(43), No. 3, 2019, pp. 273-280.

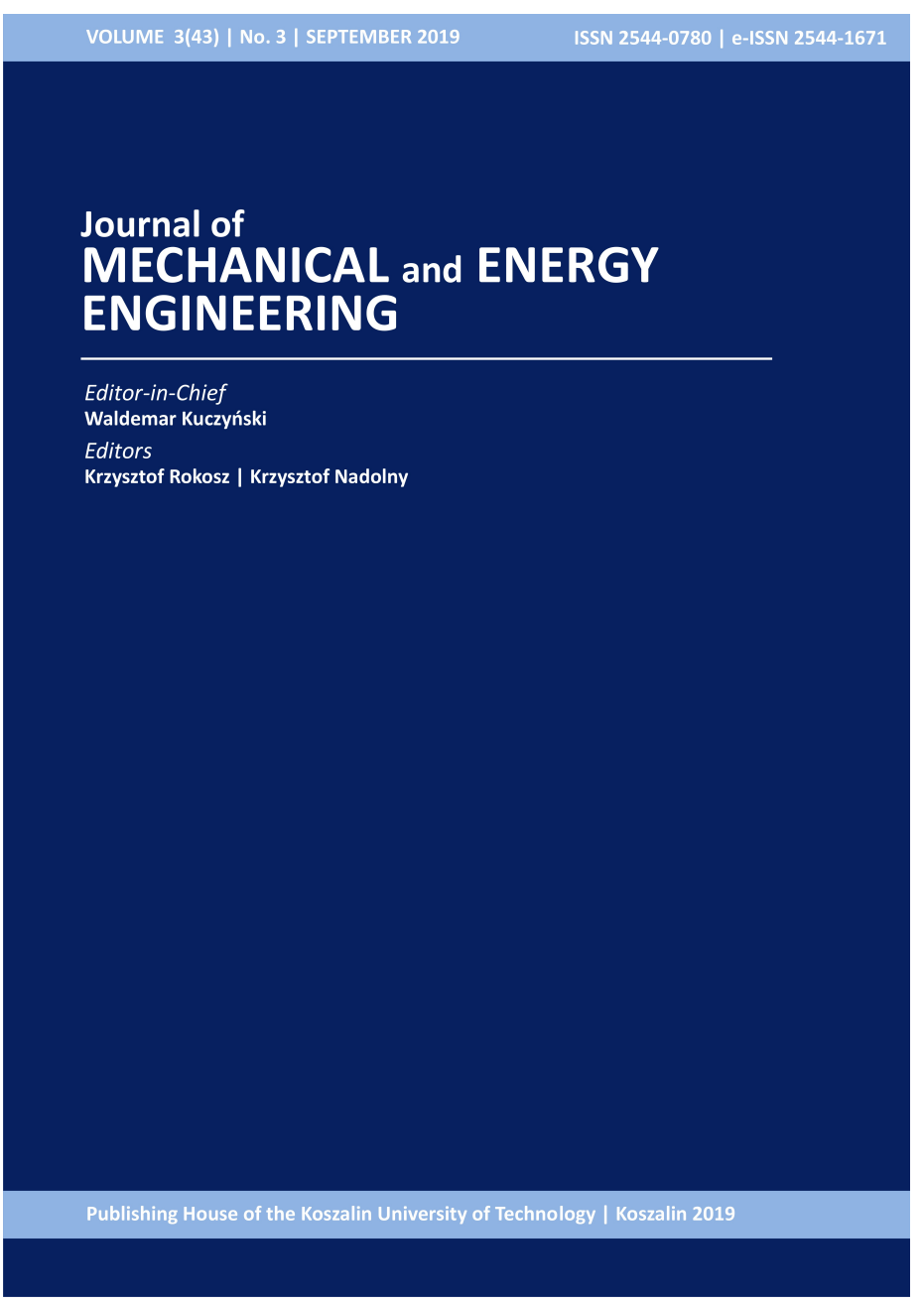

Journal of Mechanical and Energy Engineering

Website: jmee.tu.koszalin.pl

ISSN (Print): 2544-0780

ISSN (Online): 2544-1671

Volume: 3(43)

Number: 3

Year: 2019

Pages: $273-280$

Article Info:

Received 23 July 2019

Accepted 20 November 2019

\section{Open Access}

This article is distributed under the terms of the Creative Commons Attribution 4.0 (CC BY 4.0) International License (http://creativecommons.org/licenses/by/4.0/), which permits unrestricted use, distribution, and reproduction in any medium, provided you give appropriate credit to the original author(s) and the source, provide a link to the Creative Commons license, and indicate if changes were made. 


\title{
A NEW CORRELATION FOR PREDICTING THE HYDROTHERMAL CHARACTERISTICS OVER FLAT TUBE BANKS
}

\author{
Djamel SAHEL ${ }^{1}$, Houari AMEUR ${ }^{2 *}$, Warda BOUDAOUD ${ }^{3}$ \\ ${ }^{1}$ Department of Technical Sciences, University Amar Thilidji of Laghouat, Algeria \\ ${ }^{2}$ Department of Technology, University Centre of Naama -Ahmed Salhi, Po. Box 66, Naama 45000, Algeria, \\ e-mail: houari_ameur@yahoo.fr; ameur@cuniv-naama.dz; Tel: +213770343722 \\ ${ }^{3}$ Faculty of Mechanical Engineering, USTO-MB, Oran, Algeria
}

(Received 23 July 2019, Accepted 20 November 2019)

\begin{abstract}
The flat tubes are necessary apparatus to design the modern heat exchangers. In this context, a CFD (computational fluid dynamics) study has been achieved to explore the influence of the flat tube size on the heat transfer characteristics in cross-flow over flat tube banks. The calculations are performed with the help of the computer software (Fluent) which is based on the finite volume method to solve the continuity, momentum and energy equations. The numerical investigations are achieved for laminar flow (Reynolds numbers changing from 50 to 800), two dimensional flows and incompressible fluids. Some predicted results are compared with available experimental data of the literature and a satisfactory agreement is observed. The obtained results show a decrease in the heat transfer coefficient with increased size of the flat tube. A new valuable empirical correlation is suggested for the prediction of heat transfer coefficients over a flat tube bank. The proposed correlation may be useful for engineers to predict the heat transfer rates in such devices without requirements of experimental measurements.
\end{abstract}

Keywords: fluid flow; heat transfer; flat tube size; tube bank; computational fluid dynamics

\section{INTRODUCTION}

The tube banks are an important equipment to design the fin and tube heat exchangers. In such devices, the tube design is an important parameter to enhance the heat transfer phenomenon. Habitually, the tube with circular shape is widely used in designing the fin and tube heat exchangers [1-11]. The performances of heat exchangers using the gas side technique are low compared with those using the liquid flow and phase change techniques, where the thermo-physical properties yield habitually a dominant air side convection resistance [12-19]. The orientation of tubes requires also an optimized arrangement to get enhanced heat transfer characteristics [20]. In a detailed paper, Tahseen et al. [21] reported that the flat tubes are a very important equipment in various industrial applications such as air conditioning, automotive radiators and other applications. In addition, and in a comparison to the circular tube heat exchangers, they found enhanced air-side heat transfer coefficients and smaller air-side friction factor for flat tubes. In the same context, Benarji et al. [22] confirmed that the vibration and sound are expected to be less in flat tube shapes compared to the circular tube. They proposed also correlations for the prediction of Nusselt numbers and friction factor, taking in consideration the effect of longitudinal and transversal ratios on the heat transfer and pressure drop.

Although the flat tube is recommended in designing the heat exchangers, there are few papers in literature which studied the heat transfer and fluid flow behavior over the flat tube banks [23-26].

From the analysis of works presented above, it is seen that almost all bluff bodies have been studied (square, cylindrical and elliptical shaped tubes), except the flat tubes. While the flat tubes have lower pressure loss behaviors and have potential applications in modern heat exchangers and radiators of automotive. So, the best design giving the optimal performances 
requires a deep knowledge on their transient fluid flows and heat transfer characteristics.

The objective of this paper is to explore via numerical simulations the hydrothermal characteristics over a bank of flat tubes for two-dimensional, laminar and incompressible fluid flows. In addition, the effect of the flat tube size ratio $\left(R_{\mathrm{TS}}=E_{\mathrm{T}} / D_{\mathrm{a}}\right)$ is studied as a new geometrical parameter which may influence the heat transfer coefficient. Based on the results given in this paper and the correlation of Benarji et al. [22], a new correlation is developed for the prediction of heat transfer coefficients.

\section{CASE STUDIED}

The configurations of the flat inclined tube bank and the arrangement of the flat tube are presented in Figures 1.a and 1.b, respectively.

The outer diameter of tube $\left(D_{\mathrm{a}}\right)$ is $10.55 \mathrm{~mm}$, the transverse tube pitch ratio $\left(P_{\mathrm{t}}=H / D_{\mathrm{a}}\right)$ is 1.4 and the longitudinal tube pitch ratio $\left(P_{1}=L / D_{\mathrm{a}}\right)$ is $2.2 \mathrm{~mm}$. The flat tube size ratio $\left(R_{\mathrm{TS}}=E_{\mathrm{T}} / D_{\mathrm{a}}\right)$ is the new geometrical parameter studied in this work, where the range of $R_{\mathrm{TS}}$ is: 0 (i.e. a circular tube), $0.379,0.758$, $1.137,1.516,1.896,2.275,2.654,3.033,3.412$, 3.790, $4.17,4.549$ and 4.928 . Figure 1.a shows the typical heat exchanger module (HEM) arrangements that have been considered in this work, where fourteen cases were investigated.

a)

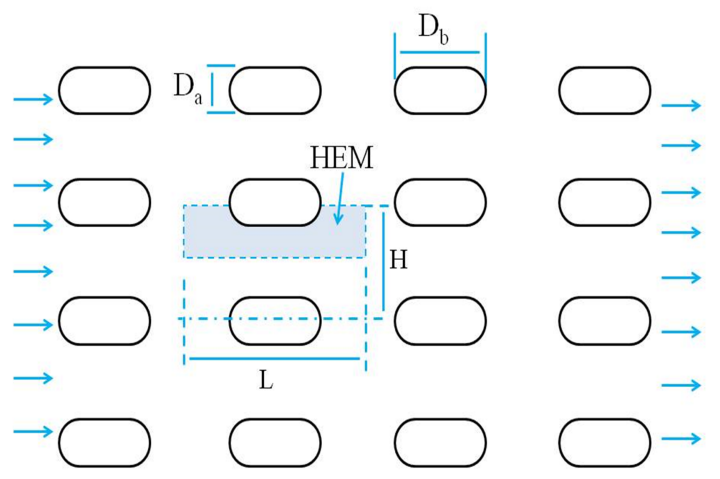

b)

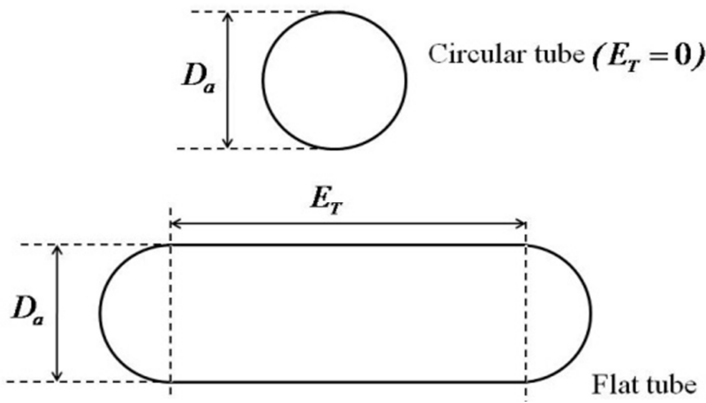

Fig. 1. Heat exchanger geometry: a) flat inclined tube bank, b) flat tube design

\section{GOVERNING EQUATIONS}

The numerical model for fluid flow and heat transfer over the tube bank is developed under the following assumptions:

- steady two-dimensional fluid flow and heat transfer,

- the flow is laminar and the fluid is incompressible,

- constant thermo-physical properties of fluid,

- negligible radiation in heat transfer,

- constant temperature on the tube surface.

Based on the above assumptions, the flow in the tube bank is governed by the continuity, Navier-Stokes and the energy equations.

Continuity Equation:

$$
\frac{\partial}{\partial x_{i}}\left(\rho u_{i}\right)=0 .
$$

Momentum equation:

$$
\frac{\partial}{\partial x_{i}}\left(\rho u_{i} u_{j}\right)=\frac{\partial}{\partial x_{i}}\left[\mu\left(\frac{\partial u_{j}}{\partial x_{i}}\right)\right]-\frac{\partial p}{\partial x_{j}} .
$$

Energy equation:

$$
\frac{\partial}{\partial x_{i}}\left(\rho u_{i} T\right)=\frac{\partial}{\partial x_{i}}\left(\frac{k}{C_{p}} \frac{\partial T}{\partial x_{i}}\right) .
$$

\section{GOVERNING PARAMETERS}

The parameters employed to estimate and compare the performance of heat transfer surfaces are defined as follows.

Reynolds number:

$$
R e=\rho U_{m} D_{h} / \mu .
$$

Total heat transfer rate is:

$$
Q=\dot{m}_{f} C_{p}\left(T_{\text {out }}-T_{\text {in }}\right) .
$$

The logarithmic mean temperature difference is:

$$
\Delta T_{l m}=\frac{\left(\left(T_{\text {wall }}-T_{\text {in }}\right)-\left(T_{\text {wall }}-T_{\text {out }}\right)\right)}{\ln \left(\left(T_{\text {wall }}-T_{\text {in }}\right) /\left(T_{\text {wall }}-T_{\text {out }}\right)\right)} .
$$

The heat transfer coefficient:

$$
h=Q /\left(A \Delta T_{l m}\right) .
$$

Nusselt number:

$$
N u=h D_{h} / k .
$$

Pressure difference

$$
\Delta P=P_{\text {in }}-P_{\text {out }} .
$$


Friction factor:

$$
f=\Delta P /\left(0.5 \rho U_{m}^{2}\right) .
$$

\section{BOUNDARY CONDITIONS}

At the inlet, a uniform velocity $U=U_{\text {in }}$ and a constant temperature $T_{\text {in }}=300 \mathrm{~K}$ are employed. The Neuman boundary condition is set at the outlet section, i.e. the streamwise variable gradients are set to be zero. Symmetry boundary conditions are employed for the side surfaces. For the tube wall, no-slip wall and impermeable boundary conditions are set. The constant temperature walls tubes $\left(T_{\mathrm{W}}\right)$ is maintained at $350 \mathrm{~K}$.

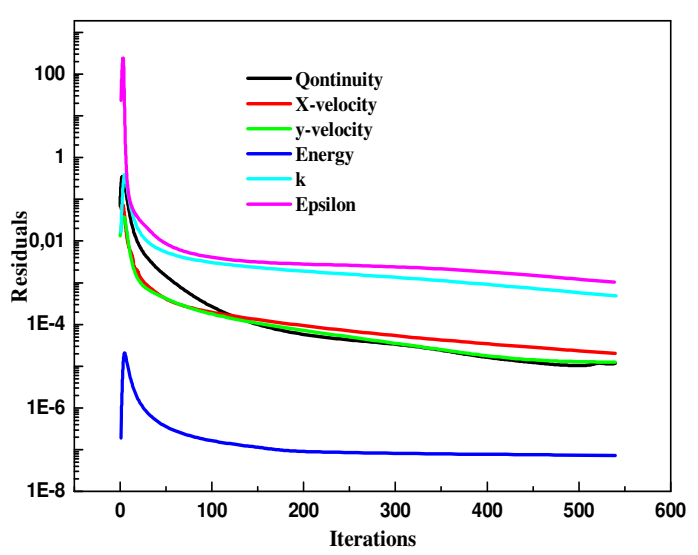

Fig. 2. Example of iterations evolution

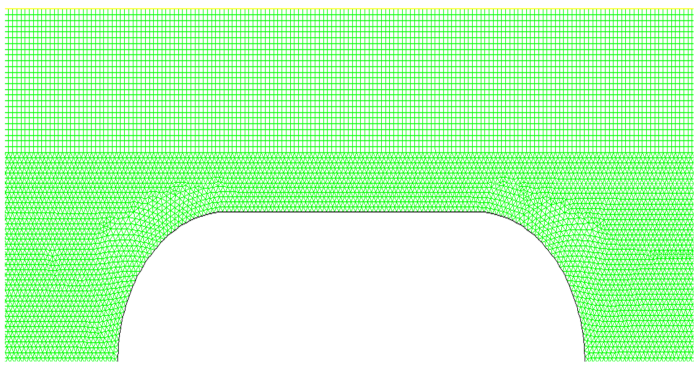

Fig. 3. Typical mixed grid

\section{NUMERICAL MODELS}

The based FVM (finite volume method) computer software FLUENT is used for simulations. For the computational domain, structured mixed mapped meshes were produced with the software GAMBIT 2.4.6. Refined meshes were created near the flat tube to predict the temperature and velocity gradients in these regions. Steady segregated solver was employed with the second order up winding scheme for the convective terms in the momentum equation. The SIMPLE algorithm was employed to model the pressure-velocity coupling. For the residual target
(Fig. 2), values of $10^{-6}$ and $10^{-9}$ were applied for the momentum and energy equations, respectively.

For the computational domain meshing, a mixed element mesh was created (Fig. 3). For the circular tube, mesh tests were realized with the following series of grids: 14460, 15924, 164118, 176411, 18277 and 198575 mesh elements. The stability of results is obtained from 176411 elements, where the variations of the Nusselt number did not go above $2 \%$ with the increased grid density. Hence, the final grid number that was accepted and used in the following investigation is 176411 elements. The same strategy was performed for the other tube arrangements, where the adopted grids element varied from 17154 to 19892 elements.

\section{RESULTS AND DISCUSSION}

\subsection{Validation of result}

After the mesh tests of different numerical domains, the flow and heat transfer behaviors are compared with available data. The present investigation is achieved over the tube bank with the same geometrical details and with a fluid having the same thermo-physical properties as those presented by Zukauskas [2] and Gholami et al. [23]. The variation of Nusselt number is presented in Fig. 4 and compared with the data from previous works [2, 23]. The analysis show a satisfactory agreement with the results of Gholami et al. [23] and $\pm 13 \%$ of deviation with the Zukauskas's correlation [2].

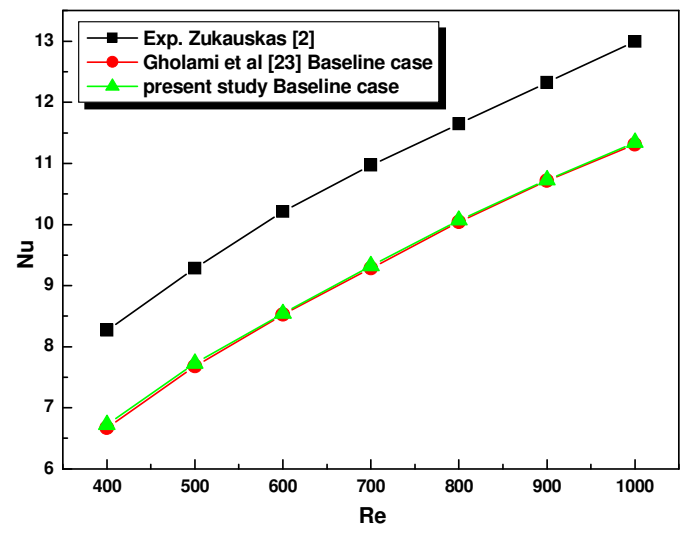

Fig. 4. Comparison of results

\subsection{Effect of the tube size ratio $\left(S_{\mathrm{TS}}\right)$}

Figs. 5 ( $a, b$ and c) clear the axial velocity distribution for the cases $S_{\mathrm{TS}}=0$ (circular tube), 2.227 and 4.92, respectively. As indicated in this figure, the admission main flow passes above the tube while a zone of the secondary recirculation appears before and behind the tube. The principal jet has a powerful flow velocity than that for the secondary zones. Unfortunately, the formation of the secondary recirculation zones behind the tubes is an undesirable 
phenomenon for the thermal transfer execution (Fig. 4-a b and c). Moreover, the tube widening is an additional problem on the thermal performance of such devices, where the flat shape of the tube yields a developed hydrodynamic boundary layer.

Consequently, the thermal boundary layer is also appearing on the flat surface of tube, as illustrated in Fig. 6 ( $a, b$ and c). Then, the heat transfer coefficients are reduced with the formation of the secondary recirculation zones and thermo-hydraulic boundary layers. Fig. 6 reveals also that the increase of the tube size ratio $\left(S_{\mathrm{TS}}\right)$ reduces the heat transfer coefficient due to the causes discussed previously.

a)
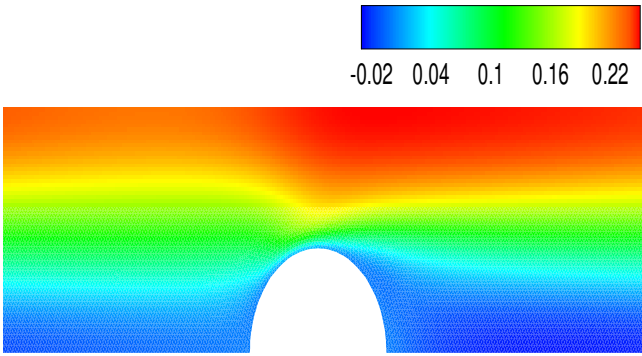

b)

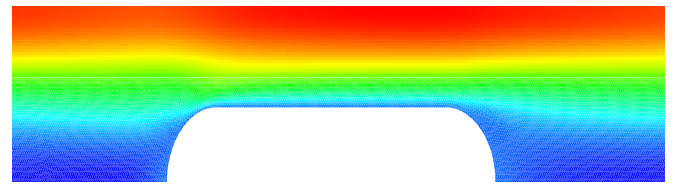

c)

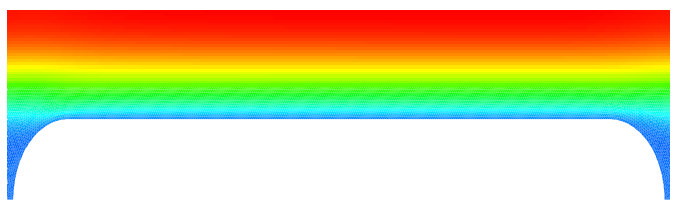

Fig. 5. Axial velocity distribution at $R e=100$; a) $S_{\mathrm{TS}}=0$ (circular tube), b) $S_{\mathrm{TS}}=2.227$, c) $S_{\mathrm{TS}}=4.92$

Fig. 7 presents the distribution of the local Nusselt number around the tube for the cases of $S_{\mathrm{TS}}=0$ (circular tube), 2.227 and 4.92, at $R e=100$. It is clearly observed that the Nusselt number is higher in the circular tube compared with the other cases. As explained above, the augmentation of the tube size ratio helps to develop thermal and hydrodynamic boundary layers, which reduce the heat transfer execution.

\subsection{Development of correlation}

Among the first authors who proposed a correlation which characterizes the flow and the heat transfer in the fin and tube heat exchangers is Zukauskas in 1972 [2]. This correlation remained for several years as a base of validation for numerical results in the heat transfer field. a) $\begin{array}{lllllllll}305 & 310 & 315 & 320 & 325 & 330 & 335 & 340 & 345\end{array}$

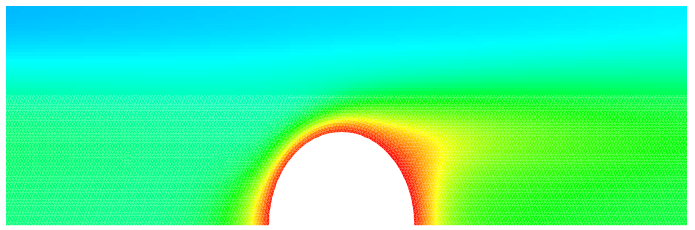

b)

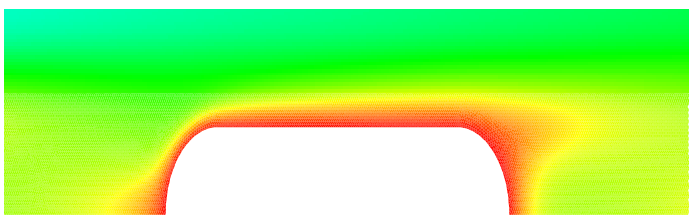

c)

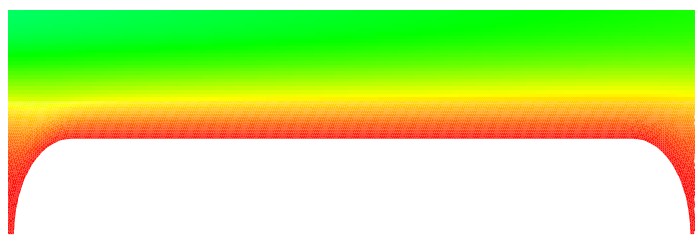

Fig. 6. Total temperature distribution at $R e=100$; a) $S_{\mathrm{TS}}=0$ (circular tube), b) $S_{\mathrm{TS}}=2.227$, c) $S_{\mathrm{TS}}=4.92$

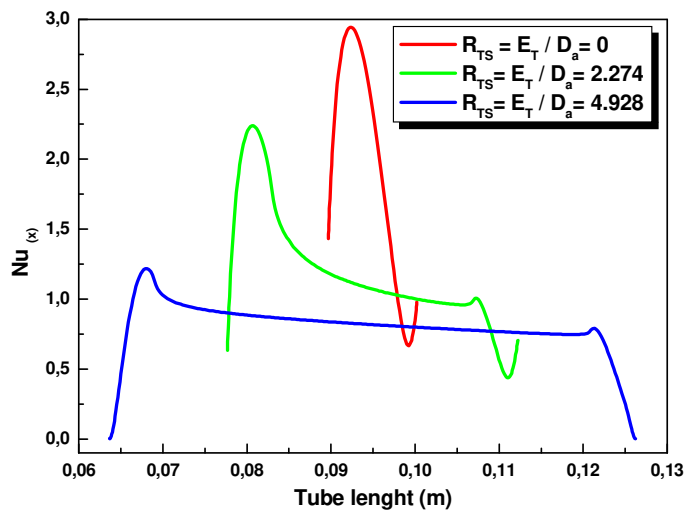

Fig. 7. Local Nusselt number distribution around the second tubes, at $R e=100$

However and in the last years, many authors proposed some new correlations in the same field [27-29], and reported that the correlation of Zukuskas requires corrections. The reports of these authors have encouraged us to propose other suitable correlations to predict the thermal coefficient of transfer.

For different Reynolds numbers, Fig. 8 presents the variation of the normalized Nusselt number that are obtained with the correlation of Benarji et al. (Eq. 11) [22], and this is under the same conditions. We remark that the Nusselt number decreases with increased tube size ratio $\left(R_{\mathrm{TS}}\right)$ and increased Reynolds number. Then and aiming to the development of a global correlation, effects of Reynolds numbers and the tube size ratio $\left(R_{\mathrm{TS}}\right)$ should be taken into account. 


$$
\begin{aligned}
& N u=0.059 \times(R e)^{0.9454} \times\left(H / D_{a}\right)^{1.4968} \\
& \times\left(L / D_{a}\right)^{0.0312}
\end{aligned}
$$

Table 1 presents the best fit of each curve of Reynolds number value. The evolution of the normalized Nusselt number according to the tube size ratio is presented in form of exponential formulas, where the coefficients of correlations $\left(R^{2}\right)$ varied in a suitable range from 0.974 to 0.987 .

\begin{tabular}{|c|c|c|c|c|}
\hline \multicolumn{2}{|c|}{$\frac{N u}{N u_{(\text {Benarii et }}}$} & $-=C_{(R}$ & $\left(-0.218 R_{T S}\right)$ & (12) \\
\hline$R e$ & 25 & 50 & $100 \quad 200$ & 400 \\
\hline$C_{(\mathrm{Re})}$ & 1.495 & 1.157 & 0.8660 .634 & 0.416 \\
\hline$R^{2}$ & 0.974 & 0.975 & $\begin{array}{lll}0.982 & 0.977\end{array}$ & 0.987 \\
\hline
\end{tabular}

Tab. 1. Nusselt correlation for different $R e$

In addition, Fig. 9 shows the reduction in the factor $C_{(\mathrm{Re})}$ according to the Reynolds number. An equation with a coefficient of correlation equal to 0.99 is given in this figure.

$$
C_{(\mathrm{Re})}=0.6778 \times R e^{-0.459} .
$$

The combination between the three equations (Eqs. 11, 12 and 13) gives us the following final correlation (Eq. 14):

$$
\begin{aligned}
& N u=0.4 \times R e^{0.4894} \times\left(H / D_{a}\right)^{1.4968} \\
& \times\left(L / D_{a}\right)^{0.0312} \times \operatorname{Exp}\left(-0.218 R_{T S}\right) .
\end{aligned}
$$

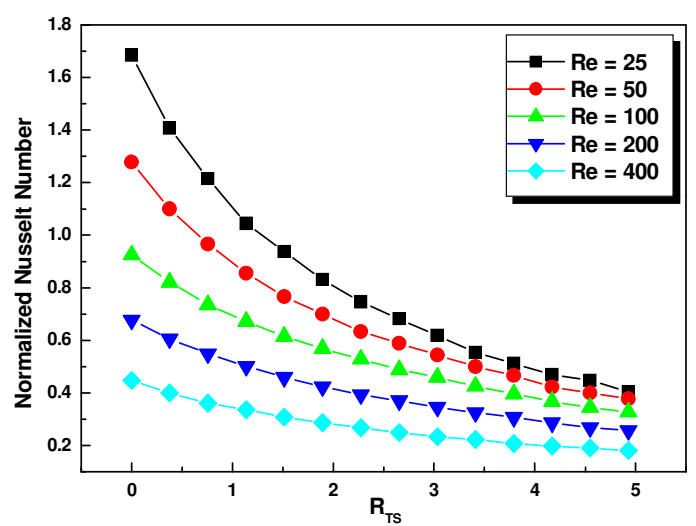

Fig. 8. Variation of the normalized Nusselt number vs. the flat tube size ratio $\left(R_{\mathrm{TS}}\right)$

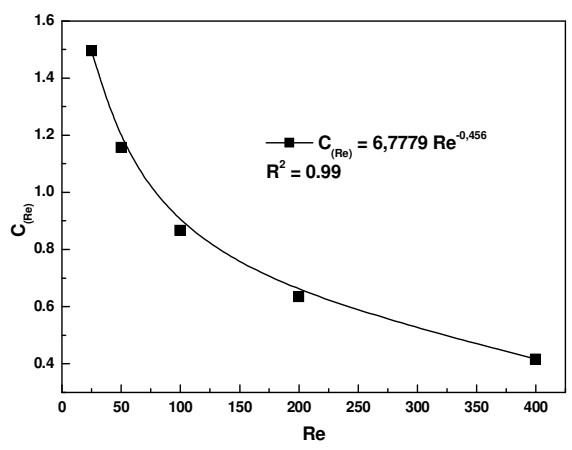

Fig. 9. Best fit of $C_{(\mathrm{Re})}$ vs. Reynolds number

\subsection{Validation of proposed correlation}

In order to estimate the reliability of the proposed correlation, assessments against existing results in literature have been conducted (Figs. 10 and 11). The paper of Haitham et al. [30] is considered in the assessment. For Reynolds number ranging from 25 to 400, two cases are reported in the validation: the first one (Fig. 10) for $H / D_{\mathrm{a}}=2, L / D_{\mathrm{a}}=4$, a deviation of $30 \%$ and $17 \%$ is observed in the beginning and at the end of Reynolds number range. For the same approach, a difference of $9 \%$ and $57 \%$ is observed in the second case $\left(H / D_{\mathrm{a}}=4, L / D_{\mathrm{a}}=7\right)$ at Fig. 11 . These deviations confirm that the tube size is an important parameter that has a great influence on the heat transfer coefficient over inclined flat tube banks.

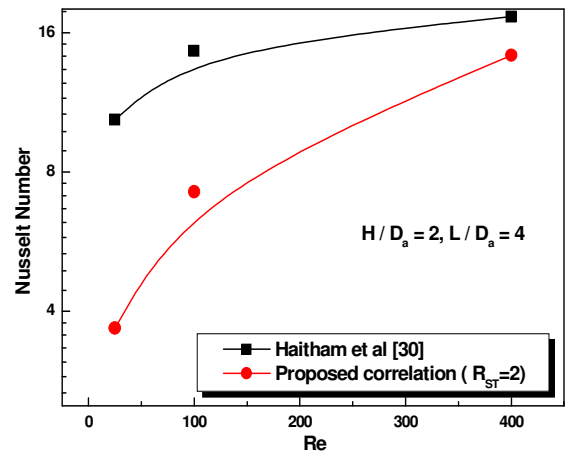

Fig. 10. Validation of the proposed correlation, for $H / D_{\mathrm{a}}=2$, $L / D_{\mathrm{a}}=4$

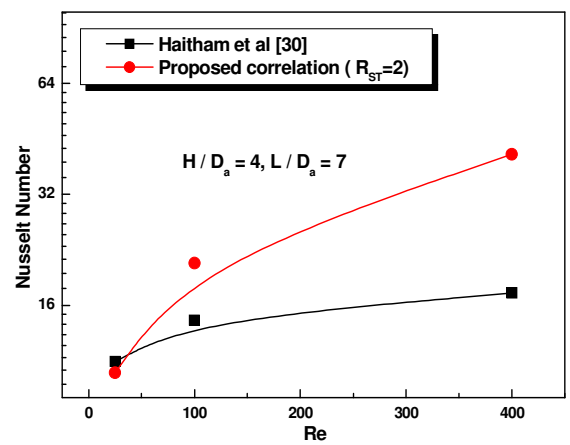

Fig. 11. Validation of the proposed correlation, for $H / D_{\mathrm{a}}=2$, $L / D_{\mathrm{a}}=4$ 


\section{CONCLUSIONS}

The hydrothermal characteristics over a bank of flat tubes were determined via numerical simulations. The effect of the flat tube size on the heat transfer behavior has been examined, based on numerical investigations by means of the Fluent software. The simulations were performed for two dimensional, laminar and incompressible fluid flows with Reynolds numbers ranging from 50 to 800 . An adequate agreement was observed in the comparison with available data. The obtained results showed that the augmentation of the flat tube size decreases the heat transfer coefficient over the flat tubes bank. Therefore, the normalization of the numerical Nusselt numbers with those calculated by Benarji et al. [22] allowed us to validate the present results and to develop a new correlation for the prediction of heat transfer coefficient over flat tubes banks.

\section{Nomenclature}

$$
\begin{array}{ll}
\text { Symbols } & \\
C_{p} & - \text { specific heat }[\mathrm{J} / \mathrm{kg} \cdot \mathrm{K}] \\
D_{h} & - \text { hydraulic diameter }[\mathrm{m}] \\
D_{\mathrm{a}} & - \text { diameter of the circular tube }[\mathrm{m}] \\
D_{\mathrm{b}} & - \text { flat tube length }[\mathrm{m}] \\
E_{t} & - \text { width of flat tube }[\mathrm{m}] \\
f & - \text { friction factor } \\
h & - \text { heat transfer coefficient }\left[\mathrm{W} / \mathrm{m}^{2} \mathrm{~K}\right] \\
H & - \text { transversal distance }[\mathrm{m}] \\
k & - \text { thermal conductivity }\left[\mathrm{W} / \mathrm{m}^{2} \mathrm{~K}\right] \\
L & - \text { longitudinal distance }[\mathrm{m}] \\
N u & - \text { Nusselt number }\left[h . D_{h} / k\right] \\
\Delta P & - \text { pressure drop }[\mathrm{Pa}] \\
P_{t} & - \text { transverse tube pitch ratio }\left[H / D_{\mathrm{a}}\right] \\
P_{l} & - \text { longitudinal tube pitch ratio }\left[L / D_{\mathrm{a}}\right] \\
Q & - \text { heat transfer rate }[\mathrm{W}] \\
U_{m} & - \text { mean velocity at the minimum flow cross- } \\
& \quad \text { sectional }[\mathrm{m} / \mathrm{s}] \\
R e & - \text { Reynolds number }\left[\rho . U_{\mathrm{m}} \cdot D_{\mathrm{h}} / \mu\right] \\
R_{T S} & - \text { flat tube size ratio }\left(E_{t} / D_{a}\right) \\
T & - \text { temperature }[\mathrm{K}] \\
\mu & - \text { dynamic viscosity }[\mathrm{kg} / \mathrm{m} \cdot \mathrm{s}] \\
\rho & - \text { density }\left[\mathrm{kg} / \mathrm{m}^{3}\right] \\
\left.m_{f}\right] & - \text { mass flow rate }[\mathrm{kg} / \mathrm{s}] \\
\text { Subscript } & \\
i n & - \text { inlet } \\
m & - \text { mean } \\
\text { out } & - \text { outlet } \\
w & - \text { wall } \\
&
\end{array}
$$

\section{References}

1. Alem K., Sahel D., Nemdili A., Ameur H. (2018). CFD investigations of thermal and dynamic behaviors in a tubular heat exchanger with butterfly baffles. Frontiers in Heat and Mass Transfer (FHMT), Vol. 10, pp. 27.
2. Zukauskas A. (1972). Heat transfer from tubes in cross flow. J. Adv Heat Transfer, Vol. 8, pp. 93-160.

3. Mellal M., Benzeguir R., Sahel D., Ameur H. (2017). Hydro-thermal shell-side performance evaluation of a shell and tube heat exchanger under different baffle arrangement and orientation. International Journal of Thermal Sciences, Vol. 121, pp. 138-149.

4. Madhani V.K., Chhabra R.P., Eswaran V. (2002). Forced convection heat transfer in tube banks in cross flow. Chem. Eng. Sci., Vol. 54, pp. 379- 391.

5. El-Shaboury E.M.F., Ormiston S.J. (2005). Analysis of laminar forced convection of air for cross flow in in-line tube banks with non-square arrangements. Num. Heat Transfer, Vol. 48, pp. 99-126.

6. Wu J.M., Tao W.Q. (2008). Numerical study on laminar convection heat transfer in a channel with longitudinal vortex generator, Part B: parametric study of major influence factors. Int. J. Heat Mass Transfer, Vol. 51, pp. 3683-3692.

7. Fiebig M., Chen Y., Grossegorgemann A., Mitra N.K. (1995). Conjugate heat transfer of a finned tube. Part B: heat transfer augmentation and avoidance of heat transfer reversal by longitudinal vortex generators. Num. Heat Transfer, Vol. 28, pp. 147-155.

8. Fan J.F., Ding W.K., Zhang J.F., He Y.L., Tao W.Q. (2009). A performance evaluation plot of enhanced heat transfer techniques oriented for energy-saving. Int. J. Heat Mass Transfer, Vol. 52, pp. 33-44.

9. Fullerton T. L., Anand N.K. (2010). Periodically fullydeveloped flow and heat transfer over flat and oval tubes using a control volume finite-element method. Num. Heat Transfer, Vol. 57, pp. 642-665.

10. Wang W., Bao Y., Wang Y. (2015). Numerical investigation of a finned-tube heat exchanger with novel longitudinal vortex generators. Appl. Therm. Eng., Vol. 86, pp. 27-34.

11. Wu J.M., Tao W.Q. (2012). Effect of longitudinal vortex generator on heat transfer in rectangular channels. Appl. Therm. Eng., Vol. 37, pp. 67-72.

12. Ameur H., Menni Y. (2019). Laminar cooling of shear thinning fluids in horizontal and baffled tubes: Effect of perforation in baffles. Thermal Science and Engineering Progress, Vol. 14, 100430.

13. Boukhadia K., Ameur H., Sahel D., Bozit M. (2018). Effect of the perforation design on the fluid flow and heat transfer characteristics of a plate fin heat exchanger. International Journal of Thermal Sciences, Vol. 126, pp. 172-180.

14. Guo Z.Y., Li D.Y., Wang B.X. (1998). A novel concept for convective heat transfer enhancement. Int. J. Heat Mass Transfer, Vol. 41, pp. 2221-2225.

15. Ameur H., Sahel D. (2019). Effect of some parameters on the thermo-hydraulic characteristics of a channel heat exchanger with corrugated walls. Journal of Mechanical and Energy Engineering, Vol. 3(43), pp. 53-60.

16. Sahel D., Ameur H., Benzeguir R., Kamla Y. (2018). Prediction of the heat transfer development in a smooth tube. Journal of Engineering Physics and Thermophysics, Vol. 91, pp. 682-687.

17. Ameur H. (2019). Effect of the baffle inclination on the flow and thermal fields in channel heat exchangers. Results in Engineering, Vol. 3, 100021.

18. Anoop B., Balaji C., Velusamy K. (2015). A characteristic correlation for heat transfer over serrated finned tubes. Ann. Nuclear Energy, Vol. 85, pp. 10521065.

19. Ameur H. (2020). Effect of corrugated baffles on the flow and thermal fields in a channel heat exchanger. Journal of Applied and Computational Mechanics, Vol. 6, pp. 209-218. 
20. Beale S.B., Spalding D.B. (1999). A numerical study of unsteady fluid flow in in-line and staggered tube banks. J. Fluids Structure, Vol. 13, pp. 723-754.

21. Tahseen T.A., Ishak M., Rahman M.M. (2015). An overview on thermal and fluid flow characteristics in a plain plate finned and un-finned tube banks heat exchanger. Renew. Sustain. Energy Reviews, Vol. 43, pp. 363-380.

22. Benarji N., Balaji C., Venkateshan S.P. (2008). Unsteady fluid flow and heat transfer over a bank of flat tubes. Heat Mass Transfer, Vol. 44, pp. 445-461.

23. Gholami A.A., Wahid A., Mohammed H.A. (2014). Heat transfer enhancement and pressure drop for fin-and-tube compact heat exchangers with wavy rectangular winglettype vortex generators. Int. Comm. Heat Mass Transfer, Vol. 54, pp. 132-140.

24. Ishak M., Tahseen T.A., Rahman M.M. (2013). Experimental investigation on heat transfer and pressure drop characteristics of air flow over a staggered flat tube bank in cross flow. Int. J. Auto. Mech. Eng., Vol. 7, pp. 900-911.

25. Tahseen T.A., Rahman M.M., Ishak M. (2014). An experimental study air flow and heat transfer over in-line flat tube bank. Int. J. Auto. Mech. Eng., Vol. 9, pp. 1487500 .

26. Tahseen T.A., Ishak M., Rahman M.M. (2014). An experimental study of heat transfer and friction factor characteristics of finned flat tube banks with in-line tubes configurations. Appl. Mech. Mat., Vol. 564, pp. 197-203.

27. Kim T. (2013). Effect of longitudinal pitch on convective heat transfer in cross-flow over in-line tube banks. Ann. Nuclear Energy, Vol. 57, pp. 209-215.

28. Sahel D., Benzeguir R., Baki T. (2015). Heat transfer enhancement in a fin and tube heat exchanger with isosceles vortex generators. Mechanika, Vol. 21, pp. 457-464.

29. Sahel D., Ameur H., Kamla Y. (2017). A numerical study of fluid flow and heat transfer over a fin and flat tube heat exchangers with complex vortex generators. Eur. Phys. J. Appl. Physics, Vol. 78, 34805.

30. Haitham M.S., Bahaidarah N.K.A. (2005). A numerical study of fluid flow and heat transfer over a bank of flat tubes. Num. Heat Transfer, Vol. 48, pp. 359-385.

\section{Biographical notes}

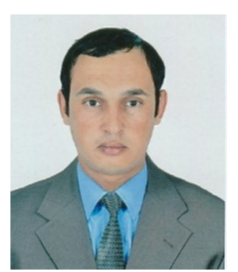

Djamel Sahel is a Doctor in the Depatment of Technical Sciences at University of Laghouat, Algeria. He obtained his engineering degree in energy mechanics in 2007. In the same specialty, he obtained his Master and $\mathrm{PhD}$ degrees in 2011 and 2017, respectively from the University of Science and Technology USTO-MB, Oran, Algeria. Her research fields are heat transfer, fluid flow, membrane systems and optimization of thermal systems.

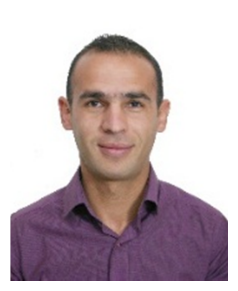

Houari Ameur is a Professor in the Department of Technology at the University Centre of Naama, Algeria. He received his Engineering Diploma in 2006 in Marine Engineering, his Master Degree in 2008, his $\mathrm{PhD}$ in 2012 and his HDR in 2013 in Mechanical Engineering from University of Science and Technology, Oran (USTO-MB), Algeria. His current research interests are mainly in the area of non-Newtonian fluid flows, mechanical agitation, Computational Fluid Dynamics, heat exchangers and thermal applications.

Warda Boudaoud is a PHD student in the Department of Mechanical Engineering, University of Science and Technology Mohamed Boudiaf of Oran (USTO-MB), Algeria. Her research interests are mainly on heat transfer, fluid flow and Computational Fluid Dynamics. 
